\title{
LA IDEA DEL MUNDO DE LOS TAINOS EN COMPARAGION CON LA DE LAS VIEJAS CULTURAS DEL ORIENTE MEDIO
}

\section{Fernando Pérez Memén}

"La humanidad ama más la poesía que la lógica, y sin un mito el pueblo perece" (1). Así con la perpicasia y el fino humor que hilvana su prosa se enfrentaba Will Durant a explicar la aparente complejidad de los mitos orientales en los que veía una poderosa carga afectiva y la ausencia de abstracciones lógicas. Pero, en rigor, la poesía no sólo es afección o subjetividad, sino también razón, pensamiento. En su núcleo late una lógica. En el caso del mito de las llamadas "sociedades primitivas" por Levi-Bruhl (2) o "arcaicas", como le denomina J. Cazeneuve (3), hay una esencia lógica envuelta en un pesado ropaje multicolor pletórico de emociones y sentimientos. A causa de esta característica en la mentalidad de esas sociedades, Levi-Bruhl las calificó de prelógicas en su libro Las funciones mentales en las sociedades inferiores. Más tarde se dio cuenta de lo inapropiado de ese vocablo, y lo cambió por el de "primitiva" Explicó que al usar aquella palabra no quiso decir que lo prelógico del pensamiento primitivo se situaba en una etapa anterior del pensamiento lógico. Y certeramente aseveró que la mentalidad primitiva es tan conceptual como la nuestra, pero que no forma sus conceptos como nosotros tejemos los nuestros, porque a diferencia de nosotros no hacen los mismos usos de las facultades intelectivas (4). 
Mucho antes, a fines del Siglo de las Luces, el solitario filosófico de Koenigsber, el de la Crítica de la Razón Pura, pudo advertir con agućeza "que el mito sin el elemento formador de logos es "todavía ciego", y la concepción lógica sin el núcleo o viviente de la originaria "intuición mítica" resulta "vacía" (5).

Al estudiar la cosmología tradicional se reafirmó en la posición fundamental de su Crítica: conocer es igual a intuición más pensamiento (6).

En rigor, la evolución de la Historia intelectual desde los albores del drama histórico hasta hoy revela una progresión lógica del espíritu humano que no ha podido desembarazarse del elemento mítico-intuitivo o subjetivo. Esto se debe a que en la estructura del espíritu humano vive como un inextinguible fuego como el fuego sagrado de los templos de Vesta- lo mítico-intuitivo, que asume, también, la comprensión del mundo por otros caminos que no son los de la razón pura, sino los de la lógica del corazón, de Blas Pascal o los del sentimiento y la voluntad de Miguel de Unamuno. Pero con todo la razón hace uso de lo mítico en su eterna preocupación por encontrar un sentido al universo y a la vida humana. Esa mentalidad mítica es "más y facilmente perceptible en los primitivos que en las sociedades modernas, pero "está presente en todo espíritu humano" (7). Esto es así, porque el hombre de hoy, como el de ayer y el del más lejano ayer ivive de símbolos!

\section{I.- El concepto demoníaco de la naturaleza en los taínos.}

Precisamente las naves que surcaron el Atlántico y anclaron por primera vez en la isla de Haití llevaban en sus mástiles el principal símbolo de la 
cristiandad: la Cruz, con la que el Almirante pretendía justificar ante el mundo conocido su intrepidez de transponer el horizonte en busca de las tierras ignotas. Y la fijación de la cruz en las tierras recién descubiertas era la justificación de la orzada que pretendía realizar de incorporar o asimilar a los pobladores presuntamente paganos a la cosmovisión cristiana para que sirviera de legitimación al dominio político simbolizado por la espada-, que aspiraba a realizar.

Colón entendió lo importante que era estudiar, conocer y comprender el mundo de las representaciones de aquella nueva humanidad que aparecía a sus ojos desnuda simple y candorosa. El Almirante, cuya formación y estructura mental, no le hacían el sujeto idoneo para esa tarea, fija su atención en las actitudes religiosas de los indígenas, los cuales le parecen

que no conocían ninguna secta ni ydolatría, salvo que todos creen que las fuerzas y bien es en el cielo (sic) (8).

Más tarde, en 1496, confirma su impresión:

Idolatría $\mathbf{u}$ otra secta no he podido conocerle ...(9).

A él mismo y a sus acompañantes por los símbolos de los poderes que manifiestan: las naves, las explosiones que salen de sus armas, y a partir del segundo viaje el trote y velocidad del caballo, más las características corporales de él y de sus hombres (tez blanca, algunos rubios, los ojos azules...), les hace pensar a los indígenas que provienen del cielo y tienen el don de la inmortalidad (10). 
Colón, empero, tuvo conciencia de sus limitaciones para comprender las ideas y creencias indígenas, así Las Casas, quien manejó sus papeles nos comunica:

Dice más el Almirante, que había tratado de saber si tenían las gentes desta Isla secta alguna que oliése a clara idolatría, y que no lo había podido comprender...(sic) (11).

Esa tarea Colón la encomendó al fraile jerónimo Ramón Pané, quien en su Relación acerca de las antiguedades de los indios echa las bases de la Etnografía americana, aunque su estudio no pasa de ser una relación descriptiva e incompleta, y con muchas deficiencias, a causa de las limitaciones intelectuales del buen sacerdote - que él mismo se sincera reconociéndolo, y Las Casas reiterativamente le echa en cara- y hasta materiales, pues carecía de suficiente papel para hacer sus anotaciones (12).

La Relación pasa al conocimiento de personas mejores dotadas que la del misionero jerónimo, a saber Pedro Mártir de Anglería, humanista y poseedor de una extraordinaria capacidad para tratar con las ideas y para darle brillo y elegancia en la exposición literaria, y el padre Las Casas, formado en la Teología Escolástica del Siglo de Oro español que concilia el tomismo con el humanismo renacentista.

Llama la atención que en aquellos momentos, es decir, los primeros años de la conquista y la colonización, que se sígnifican por el fanatismo para implantar la unidad religiosa en la Península, Colón como estos tres hombres con un fondo común en su mentalidad, pero con elementos diferenciadores en su forma de percibir la realidad, 
observan el pensamiento mitológico indígena con las mayores bondades y el mejor espíritu de comprensión. Es posible que esto se debiera a que las ideas y creencias indígenas fueran vistas no tan contradictorias esencial o sustancialmente con el pensamiento cristiano, y que sus imágenes y representaciones intelectuales eran fruto de la rusticidad y simplicidad de vida que vivían, como lo habían sido sus antepasados paganos, aunque diferentes a muchos de éstos, pues las creencias taínas no se percibíar como efectos de la malicia y pecaminosidad. Pcro tampoco sus ideas eran como las de otras naciones paganas y herejes de aquel tiempo que tenían un pensamiento sistemático y fijado en una literatura, como por ejemplo, el Budismo, el Mahometanismo, el Taoismo, el Confucionismo, y las viejas herejías de Arrio, Nestorio y Donato, y ya entrado el siglo XVI, las modernas heterodoxias. es decir, el luteranismo, el eramismo y el calvinismo.

Muchas ideas teogónicas y cosmogónicas de los tainos que ofrece Pané tienen similitudes 0 afinidades con las de los pueblos primitivos y las viejas civilizaciones del Oriente Medio, y hasta con las culturas clásicas griegas y latinas, que junto con el pensamiento judeo-cristiano, constituyen la base de la čultura occidental cristiana.

Hay en el pensamiento mítico taíno una concepción demoníaca del cosmos, donde el universo se percibe como un pandemonium de poderes espírituales, en el que la explicación mítica trata de encontrar un sentido frente a los fenómenos de la naturaleza y a la angustia existencial del hombre al darse cuenta de su precariedad, la que se agudiza al encontrarse con lo que Max Scheler llama "las situaciones límites," a saber, el nacimiento, la enfermedad y la muerte. 
$\mathrm{Al}$ igual que las mitologías de las culturas primitivas o arcaicas en los taínos se observan sus cuatro postulados fundamentales: 1) la existencia de un mundo de espíritus (dioses) buenos y malos, poderosos unos, débiles otros, invisibles y eternamente activos en los asuntos de los hombres; 2) el hombre posee un espíritu que es el alma; 3) el alma sobre todo después de la muerte, tiene vida autónoma; 4) si el hombre requiere medrar, es necesario obtener la buena voluntad de los espíritus, tanto buenos como malos (13). En ese universo demoníaco hay, además, una substancia que envuelve no sólo a los seres animados sino también a los inanimados de ahí la metamorfosis o el tránsito de un ser a otro.

Pedro Mártir, que posiblemente recibió en Medina del Campo en 1497 la Relación de manos de Colón, junto con las impresiones de éste acerca de las creencias indígenas, en carta fechada en abril de 1498 a los obispos de Braga y Pamplona, les refiere esa concepción demoníaca del universo de los taínos:

Se ha descubierto entre ellos un nuevo género de idolatría ¿Habeís visto alguna vez pintados, con las manos ganchudas y boca abierta, como para espantar a los hombres? Imitando exactamente tales vestigios, construyen ellos simulacros con tejidos de algodón y con algodón también los rellenan; porque se les aparecen durante la noche y los imbuyen en los errores en que viven. A tales simulacros llaman Zemes, de los cuales cuentan la fábula de que obtienen la lluvia, si la necesitan. y días claros, si 
quieren sol. Piensan que los Zemes, cuando están irritados, son los que envían los truenos, rayos y granizo... Entre éstos los hay machos y hembras. Creen que los machos cohabitan algunas veces con las mujeres de los reyes por un tumor muy variado que se le extiende por la cabeza (14).

Con cierta variante hace la misma descripción de ese universo demoníaco al cardenal Ludovico de Aragón, en una carta que luego va a formar parte de la Década de Primera, Libro IX (15).

Las Casas, por su parte. apoyado en $I_{n} \quad \therefore$ describe y explica el mundo espiritual de los taínos donde observa la poderosa gravitación de la divinidad en su vida cotidiana.

Creían que les daba (los cemies) el agua, $y$, el viento y el sol, cuando había menester, y lo mismo los hijos y las otras cosas que deseaban tener...Cuando algún indio iba camino y veía algún árbol que con el viento más que otro se movía, de lo cual el indio tenía miedo, llegabásele a él y preguntábale ¿Tú quien eres? Y respondía el árbol: llámame aquí un behique y el te dirá quien soy (16).

En el pensamiento mítico sumerio y semita se percibe un universo demoníaco. Entre los a.1tiguos sumerios el aire estaba lleno de espíritus, creían que los sueños eran revelaciones taínas por los espíritus del mundo inferior. En esas viejas culturas se adoraban como residencias de las 
divinidades a los árboles, fuentes, ríos y montañas (17). Ese repertorio de espíritus invasores de la naturaleza se percibe en los griegos de los tiempos de Homero y Hesíodo, como se revela en las obras del primero La Míada y La Odisea, y en La Teogonía, del segundo, donde nos habla que cuando se ensartaba una aguja el hilo tropieza en el aire con un dios. Asimismo en los antiguos latinos, pues Varrón contó unos treinta mil dioses y Petronio porque había ciudades italianas que tenían más dioses que hombres (18).

Entre los espíritus de los taínos sobresalía una divinidad máxima. Pané refiere que los indígenas:

Creen que hay en el cielo un ser inmortal, que nadie puede verlo y que tiene madre, más no tiene principio; a éste le llaman Yocahu Vagua Maórocoti (19).

Además del atributo de eternidad, Anglería le asigna casi todos los demás del Dios de los cristianos:

...Su creencia es que por medio de éstos Zemes consiguen que llueva, cuando les hace falta la lluvia, o que haya sol, cuando. lo necesitan, por considerarlos como mensajeros de un ser único, infinito, omnipotente e invisible (20).

De suerte que los cemies son representaciones de espíritus inferiores y subordinados como mensajeros, o siervos o soldados del "ser único, infinito, omnipotente e invisible". 
La concepción de esta divinidad permite a Las Casas ver a los taínos no tan lejos de la visión cristiana de Dios:

La gente de esta isla Española tenían cierta fe y conocimiento de un verdadero y solo Dios, el cual era inmortal e invisible que ninguno lo puede ver, el cual no tuvo principio, cuya morada y habitación es el cielo, y nombranlo Yócahu Vagua Maórocoti. A este verdadero y católico conocimiento de Dios verdadero se les mezclaron estos errores, conviene, a saber: que Dios tenía madre, cuyo nombre era Atabex, y un hermano suyo Guaca, y otros de esta manera. Debían ser gentes sin guía en el camino de la verdad, antes había quien de ella los desviáse, ofuscándoles la lumbre de la razón natural que pudiera guiarlos (21).

Esta idea de un Ser Supremo por encima de las demás deidades era seguida no sólo entre los taínos sino también en otros lugares de América, lo cual era un positivo condicionante para la conversión de los indígenas, pues esa concepción estaba a un paso del monoteísmo cristiano. Así el padre José de Acosta en su Historia Natural y Moral de las Indias titula el capítulo 3 del libro V, de la siguiente manera: Que en los indios hay algún conocimiento de Dios. Y asevera:

Primeramente aunque las tinieblas de la infidelidad tienen oscurecido el entendimiento de aquellas naciones, peru en muchas cosas no deja la luz 
de la verdad y razón algún tanto de obrar en ellos; y así comunmente sienten y confiesan un Supremo Señor y Hacedor de todo (22).

Justamente se identificaba el Dios de los taínos con el de los incas, Viracocha, a quien se consideraba como el creador del cielo y de la tierra (93).

Arrom observa certeramente que de las creencias taínas ninguna fue tan difundida por todo el hemisferio como la de un Gran Señor, espíritu invisible y benéfico y protector generoso del hombre americano. El significado del hombre de este Dios está íntimamente vinculado con la vida natural y humana, esto así, porque Yucahu significa: "espíritu de la yuca" (24), o dios del pan o de la alimentación, diríamos nosotros ampliando el significado del símbolo lingüístico. El término" Vagua" afirma Arron, apoyado en Oviedo, quiere decir "mar". y como los taínos además de agricultores eran excelentes pescadores, asignaron también a su divinidad suprema, dios del mar, como hicieron los griegos con Poseidon y los romanos con Neptuno (25). En cuanto a Maórocoti, este nombre significa: "sin abuelo, sin antecesor masculino", o como dice Pané "que tiene madre, más no tiene principio". La otra nominación del dios en Yucahuguamá que quiere decir "espíritu de la yuca" y "Gran Señor" que dicen que está en el cielo - como asevera Pané - o el Señor grande que está en el cielo conforme al tectimonio de Las Casas (26).

Estas ideas sobre el Ser Supremo revelan que el taíno se encontraba en un estadio del proceso de la evolución religiosa anterior al monoteísmo, que Max Müeller le llama Henoteismo, que es como un monarquismo divino, perceptible en las viejas civili- 
zaciones orientales. Esta divinidad suprema está vinculada con el cielo, el agua, el sol, la tierra. y la producción alimenticia. En Egipto $\mathrm{Re}$ o $\mathrm{Ra} o$ Amón ra (dios del sol) y Osiris (dios del Nilo, dios del pan); entre los sumerios Samạnsh (el sol); Babilonia (Mardux. el sol); Enlil (viento y la lluvia); fenicios (Baal, el sol); Adón (dios de la agricultura); Persia (Aura- Mazda, sol y cielo); los judíos: Yaveh o Jeová, del cual el salmita dice: "Dios está en la reunión de los dioses; en medio de los diosec juzga" (27); entre los griegos Zeus, padre de los dioses, quien tenía el poder del rayo, y en los antiguos romanos Júpiter, cuyo nombre compuesto es Iuspater, quiere decir. padre de la justicia, o por corrupción de Disupater o Diespiter, padre del cielo.

Esa idea taína del Ser Supremo se observa, también, en la Grecia presocrática. Jenofanes de Colofón a fines del siglo VI y principios del V AC.. en sus Elegías y Sátiras, articula una filosofía en torno a la divinidad máxima:

Un dios, el más grande entre los dioses y los hombres, no semejantes ni en cuerpo ni en inteligencia (28).

Ese dios "invisible" de los taínos es del que San Pablo tuvo conocimiento en la más culta de las ciudades griegas, Atenas, que edificó un altar donde los idolos fueron suplantados por un rótulo que rezaba así: Ignoto Deo. "al Dios no conocido" (29).

El Ser supremo de los taínos está íntimamente relacionado con una divinidad superior femenina y otra masculina. Se recordará que su tercer nombre es Maórocoti, es decir, sin abuela, sin antece- 
sor masculino. Pero así está vinculado con una mujer en sentido filial, Pané informa que:

...Tiene madre, más no tiene principio... y a su madre llaman Atabex, Iermaguacar, Apito y Zuimaco (30).

Anglería no registra la fraternidad entre el Ser Supremo y Guaca, pero si los cinco nombres de su madre: Attabeira, Mamona, Guacarapita, Iella y Guimazoa" (31).

Las Casas, en cambio, reitera la filiación del Ser Supremo con la referida diosa madre taína, pero también percibe una relación fraternal entre Guaca y Yucahu (32).

La relación de un Ser Supremo con una divinidad femenina que unas veces es madre sola. y otras veces, también es eșposa, y con un dios masculino que es su hermano se revela en los mitos de las viejas culturas orientales, entre los antiguos griegos y romanos, y en algunos mitos suramericanos. donde además de un dios aparece asociada a un héroe mítico (33).

La divinidad femenina asociada al dios prinpal fue simbolizada con la tierra y la actividad agrícola cuando el hombre dejó la caza y la recolección y con ellas los dioses vinculados con esas actividades é decir, los dioses de los árboles, de las montañas y los ríos. Justamente en nuestro lenguaje hay un parentesco lingüístico entre materia y madre (mater. en latin, es madre). de manera que los dioses Isis (Egipto); Isthar (sumerios); Cibeles (frigios); Deméter y Ceres (Grecia); Afrodita. Venus y Freya (Roma) revelan la primitiva asociación de la agricultura con la mujer cuando esta actividad se convirtió en el modo dominante de la vida humana, loc dioses de la vegetación 
reinaron como supremas hasta que se impusieron las deidades masculinas como reflejo en el cielo de la victoria patriarcal (34).

Estas deidades femeninas simbolizan la luna y la masculina el sol. Otras veces el cielo. Precisamente en muchos pueblos primitivos la palabra que designa al dios principal significaba cielo, así entre os mongoles era Tengri; en la china Tí; en la India védica era Dyaus Pitar, "el padre cielo". entre los griegos Zeus, "el que acumula nubes"; entre los persas Ahura- Mazda, "el azulado cielo". El punto central en la mayoría de la mitología primitiva es la fecunda asociación o unión entre la tierra y el cielo (35).

Volviendo a las divinidades femeninas éstas estaban asociadas con una divinidad masculina que simbolizaba la muerte de la vegetación en el otoño y la renovación agrícola y la cosecha en la primera. Así surgió el mito casi universal del dios que muere por su pueblo y vuelve triunfalmente a la vida. La diosa que da a luz el hijo, que a su vez es esposo, que muere y resucita por acción de ella es el simbolismo de la capital generatriz y reproductora de la mujer. Esa idea de la resurrección se muestra en los mitos solares que se mezclaron armonicamente con los ritos agrícolas y la leyenda del dios que muere y renace, también se aplicó a los equinocios otañales e invernales y la aparición y desvanecimiento del día, porque la noche era una parte del trágico drama cotidiano: el nacimiento y muerte del dios solar, pues cada "ocaso era una crucifixión y cada amanecer una resurrección" (36.) Esta relación simbólica entre una Diosa Madre y un Dios Padre y un hijo, que muere y renace se percibe en Egipto entre Isis y Osiris; entre los sumerios y babilonios (Isthar y Tammuz); en los fenicios: Astarté y Adón; en los frigios: Cibeles y 
Atis; en los persas: Mitra y Anaíta y Haoma; en Grecia Venus, Adonis y Dionisos (37).

¿A caso el cemí Vaybrama, que según el mito taíno fue quemado y al lavarlo con el zumo de la yuca" le crecieron los brazos y le nacieron otra vez los ojos, y le creció el cuerpo", ¿no es una representación alegórica de Yucahu? ¿No significaría la muerte de la semilla en el surco y la resurrección del fruto en la cosecha? Si es isí el misionero pudo comprender e insertar a su cosmovisión este mito, pues tenía una larga tradición simbólica que servía desoporteal cristianismo y que prefiguraba el caso de Jesucristo, el hijo de Dios, nacido de una vírgen, que murió y resucitó.

II El ser Supremo y la creación o formación del mundo y el hombre.

Arrom observa que el Ser Supremo de los antillanos no era un dios enamoradizo como Júpiter, un juez exitente y rengativo como Jehová, ni belicóso como Odín. Pero ¿Acaso sería como el dios de Ikanathón, creador y sustentador del universo y el orden moral; o el Dios de los cristianos que crea ex nihilo el cosmos y lo dirige con su providencia; o el Demiurgo de Platón que le da forma a la materia siguiendo unos modelos ejemplares; o el dios intelectual de Aristóteles retirado del mundo y sumergido en el piélago de sus propias esencias, o, finaimente, el Brahma, del pensamiento religioso hindú, de cuyo insondable seno emana la naturaleza y el hombre?

Lo cierto es que conforme con la Relación del ermitaño jeronimiano, las cartas y las Décadas de Mártir de Anglería y la Apologética Historia, de Las Casas, la mitología taína no presenta a 
Yucahú como un dios que crea ex nihilo personal y directamente el mundo.

Sobre el origen del mundo en la cosmovisión taína Pedro Mártir informó a su amigo Pomponio Letoe, en carta del 13/VI/1497, que:

... tienen en suma estimación cierta calabaza, porque de ella cuenta la fábula de haber brotado el mar con toda su multitud de peces. A causa de su crecida, aquella tierra, que era continente, dicen que se convirtió en innumerables islas...(38).

En el Libro IX, de sus Décadas, refiere la idea de los taínos sobre la procedencia del sol y de la luna:

... Existe una cueva, llamada Jouanaboina, en el territorio de cierto cacique nombrado Machinech, a la cual adoran y reverencian con mayor religiosidad que antaño los griegos a Corinto o a Cirra y a Nisa y la tienen adornada con varias pinturas...Preguntándoles por qué daban culto con tanta piedad a la caverna, respondieron grave y sensatamente que porque de allí había salido el sol y la luna para dar su luz al mundo. Visitan en peregrinación esas cuevas como nosotros a Roma y al Vaticano, cabeza de nuestra religión, o a Compostela y Jerusalem, sepulcro del Señor (39)

De los orígenes del hombre. Pané, por su parte, nos ofrece el testimonio que consigna en su Re- 
lación bajo el epígrafe: De que parte han venido los indios y en que modo:

La Española tiene una provincia llamada Caonao, en la que está una montaña, que se llama Cauta, que tiene dos cuevas nombradas Cacibajagua una y Amayaúna la otra. De Cacibajagua salió la mayor parte de la gente que pobló la isla.Estas gentes estando en aquellas cuevas, hacía guardia de noche, y se había encomendado este cuidado, a uno que se llamaba Mácocael. el cual porque un día tardó en volver a la puerta, dicen que se lo llevó el Sol. Visto pues, que el Sol se había llevado a éste por su mala guardia, le cerraron la puerta, y así fue transformado en piedra cerca de la puerta. Después dicen que otros habiendo ido a pescar, fueron presos por el Sol, y se convirtieron en árboles que ellos llaman jobos, y de otro modo se llaman mirabolanos... (40).

Los textos citados revelan que el mar brota de una calabaza o higuera, el sol y la luna de una cueva y la humanidad de dos cavernas. Convendría subrayar que Jouanoboina fue su principal santuario. Ciertamente una manifestación de piedad ¿Acaso porque pensaran que lo trascendente refleja su esencia en lo circular? ¿ Pensarían los talnos que en los más remotos tiempos el universo era una gran esfera donde al igual que en los mitos de las viejas culturas reinaban el caos y la oscuridad? ¿ Reflexionarían, además, que la tierra era circular, 
haciendo la analogía del disco solar y el lunar con la tierra? Estas interrogantes se plantean como aventuradas hipotesis de trabajo o como problemas que deben suscitar investigaciones sobre el miv taíno.

Convendría significar. con respeto a esta cuestión, que en algunas de las viejas culturas se observa una percepción circular del cosmos. Así los sumerios veían el universo como una esfera rodeada de agua (41). En Persia se decía que el dios de Zaratustra era "el círculo completo de los cielos" y que tenía por vestidura "la sólida boveda del firmamento', y el sol y la luna eran sus ojos. En su libro sagrado El Zend-Avesta se lee lo siguiente: "No pudo el que horadó esta anchura, redonda tierra, con extremos alejadísimos, como Dahak, que iba del Este al Oeste buscando la inmortalidad y no la encontró". En los poemas homéricos se habla de la tierra como ",el disco terrestre". Se decía que el curso que seguía el sol de Este a Oeste lo continuaba debajo de la tierra y reaparecería en el Oriente, es decir, a su punto de partida. Y no sólo era circular el curso del sol. sino también. el de la luna. El padre de la Historia, Heródoto se burlaba de las imágenes del mundo de los más antiguos mapas jónicos que dibujaban la tierra redonda y rodeada por el océano (49). En el diálogo de Platón El Timeo se recoge el mito que refiere que el demiurgo le dio al universo "La forma de esfera" (43).

En relación a los orígenes del mundo y la humanidad del mito taíno, conveniente es significar que en la mitología suramericana hay dos concepciones que tratan de ellos. Algunos grupos culturales creen que la humanidad fue creada por los dioses o héroes culturales; pero la mayoría de las colectividades indígenas piensa que la humanidad 
fue creada por los dioses o héroes culturales; pero la mayoría de las colectividades indígenas piensa que la humanidad salió del cielo o surgió del mundo subterraneo (44).

Loven piensa que los taínos de las Antillas pertenecen al grupo de culturas que creen que el hombre emergió de las profundidades de la tierra. Señala una serie de mitos de los Witotos y otros grupos de Sur América recogidos por Ehrenreich. Refiere uno, de los indios arekunas recogido por Otto Thulin en 1912 que explica cómo el sol surgió del interior de una montaña. Alfred Metraux, por su parte utilizó los estudios comparativos de Ehrenreich y estudió los mitos del área del Gran Chaco y de otras áreas culturales suramericanas, e infiere que muchos grupos que corresponden a la zona tropical explican el origen de la humanidad como proveniente de agujeros y cuevas (45).

En el mito de los orígenes del mundo y del hombre de los taínos, como señalabamos antes y ahora reiteramos, no se percibe una intervención creativa directa del Ser Supremo, quienes actúan son dioses o héroes culturales. ¿Actuó indirectamente a través de estos seres? ¿o quizás directamente en unas metamorfosis mítica? Pero lo cierto es que el pensamiento mítico taíno hace proceder la naturaleza y el hombre de realidades inmanentes: las cavernas y el interior de una calabaza. ¿Acaso este Ser Supremo. que es el espíritu de la yuca, es la versión taína de Hefestos o el Vulcano de Roma que tenía sus talleres en las profundidades del Hades para hacer cosas? Pero el Ser Supremo de los taínos también es el dios del marVagua- ¿Tal vez se identificaría con el principio originario del mundo, conforme al mito sumerio de que Mardux sacó del cuerpo de Tiamat- el agua salada, el mar- el universo (46). ¿O con Jehová, 
cuyo espíritu "se movía sobre la faz de las aguas", antes de la creación según se lee en el Génesis (47), o ¿quizá con Océano, el cual es el origen de todas las cosas, según los poemas homéricos (48) que llevó a Tales de Mileto de que el agua es el principio del ser, de la realidad?

Las ideas planteadas en este trabajo a manera de aventuradas hipótesis y otras no estudiadas de la cosmovisión taína no fueron vistas por Las Casas y los primeros misioneros como esencialmmente contrarias al pensamiento cristiano. Oigamos lo que nos confiesa el sacerdote y cronista:

...Así hacía en esta isla. y en estas obras con estas simplisimas gentes, donde no había del todo ni muy abierta y desaforada idolatría (49).

El fraile y humanista tuvo la convicción de que los indios tenían las disposiciones de carácter para asimilar la doctrina cristiana. pues sus mentes eran tablas rasas, donde la verdadera fe podía gravarse facilmente (50).

Con estos buenos auspicios el sistema de representaciones de los indígenas inició el proceso de asimilación a la imagen del $\mathrm{m}$ undo del cristianismo. proceso que no pasó de su primera fase, porque la espada primero, y el látigo después no permitieron el triunfo de la cruz.

1. Durant, Will.- Nuestra Herencia Oriental. Traducción de C.A. Jordana. Argentina. Editorial Sudamericana 1052 P 495.

2. Bruhl. Levi - Les fonctions mentabaler dans les sociétes inferieures. Alcon. 1910; Mentalité Primitive. Alcon, 1922; L ame primitive. Alcon, 1927; Le surnaturel et nature dans la mentalité primitive. Alcon, 1935; y L'Experience Mystique et les symboles chez les primitive, Alcon, 1937; Cfr J. Cazeneuve.- La mentalidad arcaica. Traducción de Patricio Canto. Buenos Aires, Siglo Veinte 1967 
4. Ibidem, 44. La mentalidad primitiva no hace más uso de esas facultades que las necesarias para desenvolverse en la práctica cotidiana. Mientras la mentalidad moderna hace uso de las operaciones lógicas de la abstracción y clasificación de conceptos, aquellas los yuxtapone y hace símbolos.

5.- Jaeger. W - Paidea: los ideales de la cultura griega. México. Fondo de Cultura Económica, 1962, P. 151.

6.- Hirschberger, Johannes.- Historia de la Filosofía. Traducción y apéndices de Luis Martínez Gómez, S. I. Barcelona. Editorial Herder, 1962. T. II, P. 157.

7.- $\quad$ Cazeneuve, Ob. Cit., 53, 54.

8.- Texto de la carta de Colón de 1493 en Ramos Pérez. Demetrio.- La Carta de Colón sobre el descubrimiento. Granada, Diputación Provincial, 1983.

9- Arrom, José Juan.- Relación de Fray Ramón Pané acerca de las antiguedades de los indios. textos, notas y apéndices. Documento del Almirante, en el apéndice, p.88.

10.- Jimenes Lambertus, Abelardo.- "La inmortalidad de los conquistadores." Revista Casas Reales, Museo de las Casas Reales, Santo Domingo, R.D. 1982. No.13, pp. 9-73.

11. Cfr Alegría, Ricardo. e.- Apuntes en torno a la mitología de los indios taínos de las Antillas Mayores y sus orígenes suramericanos. Santo Domingo, R.D., Museo del Hombre Dominicano, 1978. P. 21.

12.- Véase Relación sobre las antiguedades de indios, editado y anotado por 1. J. Arrom. México, Siglo XXI, 1974; Cfr Alegría Ob. Cit.. págs. 26 y 28.

13.- Turner, Ralph.- Las Grandes Culturas de la Humanidad. México, Fondo de Cultura Económica. 1963. Vol.1, págs. 101-102.

14.- Cfr. Alegr1a, Ob. Cit., 30-31.

15.- Mártir de Anglería, Pedro.- Décadas del Nuevo Mundo. Estudio y apéndice de Edmundo Ogormán. Traducción de Agustín Millares Carlo. México. Porrúa e Hijos, 1964. Vol. I, Pág. 191; Arrom, Ob. Cit.. Pág. 92.

16.- Las Casas, Fray Bartolomé de.- Apologética Historia de las Indias. En Arrom, Ob. Cit., apéndice, p. 106-107.

17.- Turner, Ob. Cit., I 158; Durant, Ob. Cit., 99 y 100. 
18.- Durant, Will.- César y Cristo. Traducción de Luis Tobío. Buenos Aires, Editorial Sudamericana, 1959.Vol. I, P. 107.

19.- Relación de Pané.. En Hernando colón. Historia del Almirante Don Cristóbal Colón. Madrid, Librería General de Victoriano Suárez 1932 Vol. II. Pág. 36.

20.- Mártir de Anglería, Ob. Cit., I, Deo, I, Lib. IX, Pág. 191.

21.- Las Casas, Ob. Cit., en arrom, P. 104.

22.- Acosta, José de.- Historia Nacional y Moral de las Indias. Vida religiosa y Civil de los Indios. Prólogo y selección de Edmundo $\mathrm{O}$ Gormán. México, Universidad Nacional Autónoma de México, 1978. Pág. 12.

23.- $\quad$ Ibid.

24- Arrom, J. J.- El mundo mítico de los taínos. Notas sobre el Ser Supremo.. Revista Dominicana de Arqueología y Antropología. Enero-junio 1 de 1971. Año I, Vol. i, no. I, Págs 183,184 y 185 .

2s. Ibid.

26.- Las Casas; - $-\mathrm{ab}$ cit

27.- Salmo $50: 1$; Véase Rembao, Alberto.-Lecciones de Filosofía de la Religión Matanzas, Cuba, Seminario Evangélico de Teología. Pág. $? 11$

28.- Véase Marías, Julián.- La Filosofía en sus textos Barcelona, Editorial Labor, S.A., 1963. Vol. I, Pág. 28.

29- Hechos de los A póstoles, 17: 23. La Santa Biblia. Versión de Casiodoro de Reina y Cirpriano de Valera. Sociedades Biblicas de América Latina. Revisión de 1960.

30.- Pané, Relación, en Colón, I, 36.

31. Anglería, Ob. Cit., Deo. I, Lib. IX.

32.- Las Casas. Ob. Cit., en Arrom, 104

33.- Alegría, Ob. Cit.. 9 n.

24.- Durant, Nuestra Herencia. .99, 100

35.- $\quad$ bid., $98,99$.

36.- Ibidem, 106, 107. 
37.- El culto de Mitra dio origen a la fiesta de la Navidad al cristianismo Esta fiesta originalmente era un festival solar, en el que se celebraba el solsticio de invierno (hacia el 22 de dic.). El alargamiento del día simbolizó el triunfo del sol sobre sus enemigos. Durant...Nuestra Herencia.. 495; 320 al 487; del mismo autor The Life Of. Greeve. New York, Simon and Schuster, 1939. p. 13.

39.- Mártir de Anglería, Ob Cit. I, Lib. IX, 194.

40.- En Alegría, Ob. Cit.. 58.

41.- Turner, I. 171.

42.- Durant, Ob. Cit., Nuestra Herencia, 489, 494; Jaeger, Ob. Cit., 156 y 157.

43.- Platón.- Dialogos. El Timeo. 667.

44.- Alegría, Ob. Cit., 57.

45.- $\quad$ Ibidem, 60,61 .

46.- Collingwood, R. C.- Idea de la Historia Méxicn, Fondo de Cultura Económica, 1968. Págs. 24, 25.

47.- Génesis, 1: ?.

48.- $\quad$ Las Casas, Ob. Cit., Arrom, 108.

49.- Elliot, J. H.- El Viejo Mundo y el Nuevo. 1492-1650. Madrid, Alianza, Editorial, 1972. P. 47 